\title{
APPLICATION OF COLD SPRAY COATING TECHNIQUE TO AN UNDERGROUND DISPOSAL COPPER CANISTER AND ITS CORROSION PROPERTIES
}

\author{
MIN SOO LEE ${ }^{1 *}$, HEUI JOO CHOI ${ }^{1}, \mathrm{JONG}_{\text {WON CHOI }}{ }^{1}$, and HYUNG JUN KIM ${ }^{2}$ \\ ${ }^{1}$ Korea Atomic Energy Research Institute \\ 150 Deokjin-dong, Yuseong, Daejeon, 305-353 Republic of Korea \\ ${ }^{2}$ Research Institute of Industrial Science \& Technology \\ 135 Pohang 790-600, Republic of Korea \\ ${ }^{*}$ Corresponding author. E-mail : minm@kaeri.re.kr
}

Received March 17, 2011

Accepted for Publication May 30, 2011

A cold spray coating (CSC) of copper was studied for its application to a high-level radioactive waste (HLW) disposal canister. Several copper coatings of $10 \mathrm{~mm}$ thick were fabricated using two kinds of copper powders with different oxygen contents, and SS 304 and nodular cast iron were used as their base metal substrates. The fabricated CSC coppers showed a high tensile strength but were brittle in comparison with conventional non-coating copper, hereinafter defined to as "commercial copper". The corrosion behavior of CSC coppers was evaluated by comparison with commercial coppers, such as extruded and forged coppers. The polarization test results showed that the corrosion potential of the CSC coppers was closely related to its purity; low-purity (i.e., high oxygen content) copper exhibited a lower corrosion potential, and highpurity copper exhibited a relatively high corrosion potential. The corrosion rate converted from the measured corrosion current was not, however, dependent on its purity: CSC copper showed a little higher rate than that of commercial copper. Immersion tests in aqueous $\mathrm{HCl}$ solution showed that CSC coppers were more susceptible to corrosion, i.e., they had a higher corrosion rate. However, the difference was not significant between commercial copper and high-purity CSC copper. The decrease of corrosion was observed in a humid air test presumably due to the formation of a protective passive film. In conclusion, the results of this study indicate that CSC application of copper could be a useful option for fabricating a copper HLW disposal canister.

KEYWORDS : Copper, Canister, Corrosion, High-level Waste, Underground Disposal, Cold Spray Coating

\section{INTRODUCTION}

Radioactive wastes are inevitable by-products of nuclear power plants. Spent nuclear fuel is the most difficult waste to deal with, and it cannot be disposed of at a general waste disposal site due to the potential hazards arising from its high radio-toxicity and heat generation. Its radioactivity lasts for many years, ranging from several decades to millions of years. Therefore spent nuclear fuel must be isolated from human environment for an extremely long timescale. For this reason, several countries, including Japan, Sweden, Finland, and the United States, have considered deep underground geological disposal of high-level nuclear waste (HLW) and spent nuclear fuel [1]. It is important to use a corrosion resistant material for disposal containers to ensure reliable confinement of HLW for such a long repository period (e.g. million years). Several countries, including Sweden, Finland, and Japan, have been developing a underground disposal concept, in which a water saturated underground environment is considered. In particular, Sweden and Finland have selected a $50 \mathrm{~mm}$ thick copper canister to secure HLW for extremely long periods of time [2, 3]. Japan has adopted $190 \mathrm{~mm}$-thick carbon steel as a canister material [4] and has also considered copper for additional protection layers on the carbon steel [5]. Copper is well known for its high corrosion resistance due to the very stable oxide film formed on its surface to prevent further oxidation in potential underground repository environments in Sweden, Finland, and Japan [6]. Most importantly, copper is thermodynamically stable under anaerobic conditions [7]. Sulfide, however, is known to corrode copper to $\mathrm{Cu}_{2} \mathrm{~S}$ due to the reduction of $\mathrm{H}_{2} \mathrm{O}$ in an anaerobic environment [8]. Considering these facts, it is very important to focus on the transient phase 
following a repository closure, when resaturation from an unsaturated condition and thermal effects from spent nuclear fuel would occur in the surrounding environment of the disposal canister. The geological environment in Korea has the same underground conditions as that in Sweden, Finland, and Japan; therefore, Korea is currently considering copper as a candidate canister material [9]. In general, the size of the disposal canister must be large enough to accommodate an assembly of spent nuclear fuel, which is about $1 \mathrm{~m}$ in diameter, and $5 \mathrm{~m}$ in height. To fabricate such a large seamless copper canister, several methods, such as extrusion, pierce-draw processing, and forging, were considered in Finland and Sweden [10]. However the application of these mechanical fabrication methods became more difficult as the container size increased; local differences in the microstructure occurred more frequently. Also, a thin-walled copper tube with a large radius could not be manufactured because of the inherent flexibility of pure copper $[2,11,12]$.

Previous test results indicated that the corrosion rate of copper was generally less than $10 \mathrm{~mm}$ for a one million year repository period in a deep underground geological environment where almost no oxygen exists $[13,14]$. Therefore, it can be assumed that a $10 \mathrm{~mm}$ thickness could be the minimum thickness for the design of a copper canister to at least establish 1,000 to 1,000,000 year validity to be safe, if there will be no physical intrusion such as fault movement. To overcome some of the difficulties in mechanical fabrication methods for such a large copper canister, it was necessary to research an alternative method. Based on an overall literature search and experiments, a cold spray coating (CSC) is proposed for the fabrication of a copper layer on the inner cast iron container. CSC is a coating method that drives fine copper powder into a hard plate under high-speed to form a coating film at an elevated temperature that is below the melting temperature. The merits of this technique are that the coating layer is rigid, it is easy to control its thickness, and it is free from oxidation. Another spray coating method is high-velocity oxy-fuel thermal spray (HVOF), which had also been used to form a corrosion resistant film [15]. However, the application of HVOF was not considered in this study because it is sensitive to the oxidation of copper, and it is difficult to form a thick copper layer. In addition, SKB in Sweden once considered a spray forming method to fabricate a copper canister, but they aborted its development because it may produce many pores in the pure copper coatings [16].

In this study, $10 \mathrm{~mm}$-thick copper coating samples were prepared by using CSC, and their mechanical and corrosion properties were investigated to evaluate the viability of the method for application in disposal canister fabrication. Several copper coatings of $10 \mathrm{~mm}$ thickness were fabricated on plates of base metals, such as stainless steel or cast iron. The test results were compared to commercial coppers.

\section{FABRICATION OF COLD SPRAY COATING (CSC) COPPER}

\subsection{CSC Process}

Fig. 1 shows the schematic diagram of the CSC process. A fine copper powder of 1 to $50 \mu \mathrm{m}$ in diameter was used in this study. The copper powder was heated to about $400^{\circ} \mathrm{C}$ prior to feeding it in order to soften it. Then, the copper powder was mixed with a highly pressurized carrier gas, and finally blown out at a supersonic speed of 400 to 450 $\mathrm{m} / \mathrm{sec}$ onto a base metal surface through a narrow nozzle. The carrier gas was also heated to about $600^{\circ} \mathrm{C}$ before the mixing. Inert gasses were used as a carrier gas to avoid oxidation of the metal powder. In the CSC process, coating was achieved by plastic deformation of metal particles. This CSC was very effective in avoiding undesirable

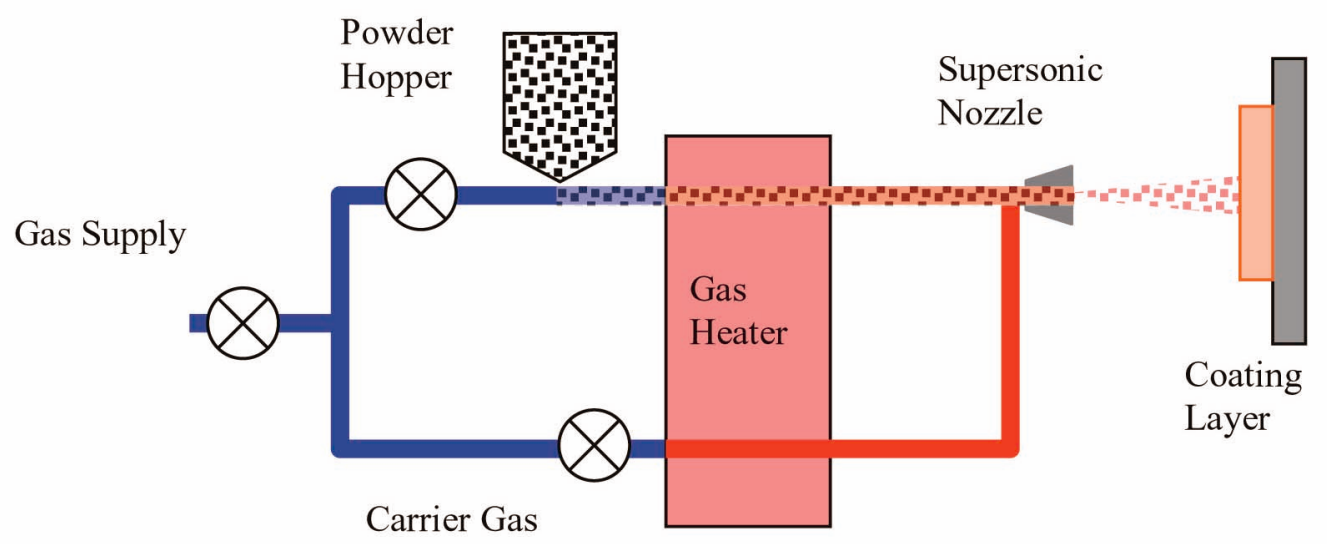

Fig. 1. Schematic Diagram of the CSC Process 
oxidation or phase transition of metal, minimizing of the thermal impact on a substrate, and creating a thick coating layer with low residual stress. Generally, the produced coating layer had high density and hardness [17].

Two kinds of copper powders were used for this study. They were low-purity copper (99.5 wt\%) supplied by Changsung Co. and high-purity copper (99.97 wt\%) supplied by Tafa ${ }^{\circledR}$. The particle sizes were 10 to $40 \mu \mathrm{m}$ and 5 to $20 \mu \mathrm{m}$, respectively. Using the CSC process, we fabricated coating layers which were more than $10 \mathrm{~mm}$ thick. The applied gas pressure was about 2.7 $\mathrm{MPa}$, and the process temperature was $600^{\circ} \mathrm{C}$. Image analysis (Image-Pro Plus) results revealed that the produced coating layers had 0.68 area\% porosity for the low-purity powder and 0.3 area $\%$ for the high-purity powder. $\mathrm{N}_{2}$ gas was used as a carrier gas. For the substrates, stainless steel SS 304 and cast nodular iron were used. Cast nodular iron is being considered as an inner container material in disposal canisters [2, 3]. Stainless steel is generally used as a container material for HLW in other nations [18]. Therefore, the two materials were adopted as a coating substrate in this study. Three kinds of coating layers were produced, namely, high-purity copper on stainless steel (\#2) and low-purity copper on both stainless steel (\#1) and cast iron (\#3).

Fig. 2 shows the high-purity copper powder (upperleft), the produced $10 \mathrm{~mm}$-thick copper layer (upperright), and a cross-sectional view (lower left), in which spherical copper particles were seen being deformed and stacked up. An interface between the copper particles in the coating was clearly observed. This interface was expected to disappear after annealing at an elevated temperature.

\subsection{Mechanical Properties of CSC Copper}

The oxygen content of the CSC copper specimens was measured using a LECO TC 136 nitrogen/oxygen determinator. The resultant oxygen content and density for the produced CSC coppers are summarized in Table 1. For comparison, commercial coppers were added: extruded copper (\#4) and forged copper (\#5) in Table 1. The CSC copper (\#2) has the highest purity, and the CSC coppers (\#1 and \#3) have the lowest purity. The bulk density was higher at lower oxygen content. The CSC coppers (\#1 and \#3) originated from the same copper powder, but their base substrates were different. In the XRD analysis, copper oxide peaks of the CSC specimens did not appear (Fig. 3). Therefore, it was concluded that oxidation did not occur during the CSC process.

A tensile specimen was cut out horizontally from the face of the coating layer at a $0.5 \mathrm{~mm}$ thickness (Fig. 4). In the tensile test, the CSC specimen broke like a glassy material, and showed little plastic deformation. Only the high-purity CSC copper (\#2) showed slightly better flexibility than the other CSC coppers, showing yielding behavior. The tensile test results (Fig. 5) showed that the CSC specimens had a higher tensile strength than those
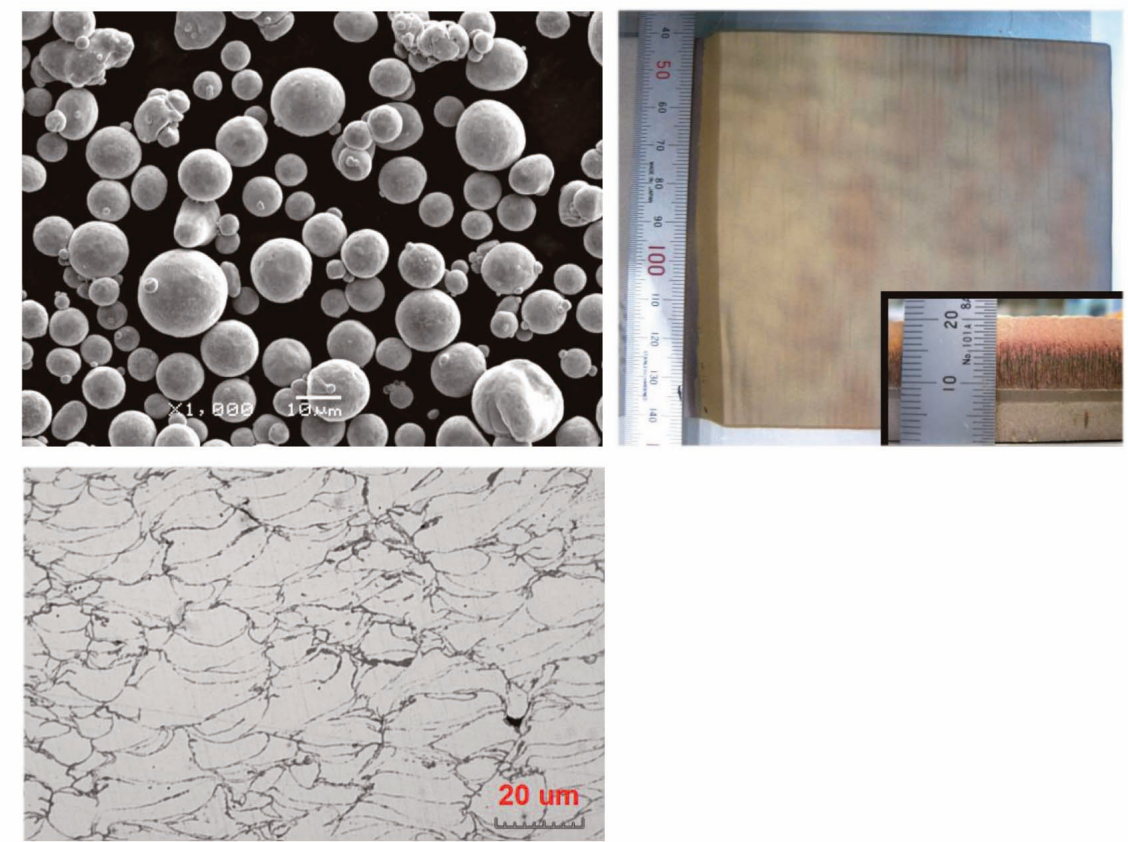

Fig. 2. Copper Powder and the CSC Product on the Metal Substrate. (Upper Left; High-purity Cu Particles (from Tafa®), Upper Right; Coating Product, Lower Left: Optical Microscopic View of the Cross-section) 
of commercial copper. The tensile strengths of the CSC coppers (\#1 \& \#3) and (\#2) copper were about $300 \mathrm{MPa}$ and $250 \mathrm{MPa}$, respectively, which were much higher than that of the extruded copper (\#4) at about $175 \mathrm{MPa}$. However, their total elongation $(1.5 \%$ to $2 \%$ ) was much

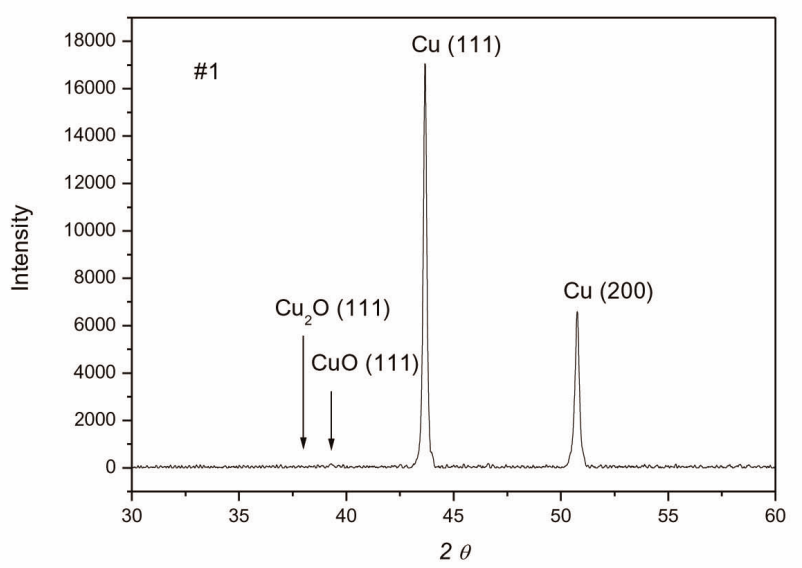

Fig. 3. XRD Graph of the CSC Specimen (\#1) on Stainless Steel SS 304 lower than that of the extruded copper (about 30\%). The Young's modulus of the CSC specimens was about two times higher than that of the extruded copper (Fig. 4), which means they have low impact characteristics. According to a previous report [19], forged copper has a tensile strength of $220 \mathrm{MPa}$ and a total elongation of $50 \%$. Thus, the CSC copper was more rigid and brittle in comparison with the forged copper. The Vickers hardness of the CSC specimen was above $1200 \mathrm{MPa}$ (120HV500) which is much higher than the value of commercial copper at $368 \mathrm{MPa}$.

In conclusion, the CSC copper had higher strength, but showed more brittleness in comparison with commercial copper. It is presumed that the brittleness of the CSC specimens would decrease after annealing at an elevated temperature. In the constitution of a disposal canister, the inner cast iron container has the function of mechanical resistance and the outer copper container has the function of corrosion resistance, so there is no specific mechanical requirement for the copper canister. However, the brittleness of CSC copper should be investigated further; it could be a critical problem during transportation or emplacement in an underground repository. The corrosion behavior of CSC copper is presented in next section.
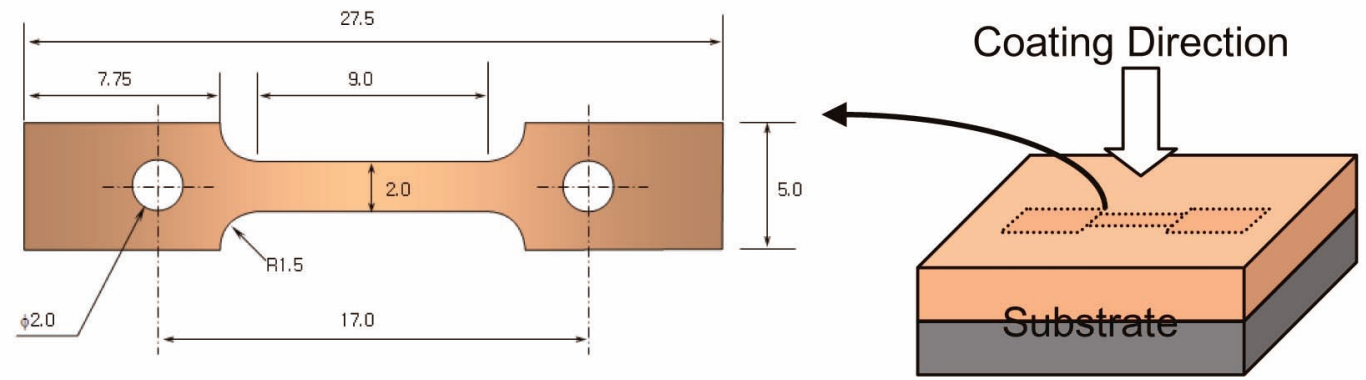

Fig. 4. Tensile Specimen Dimension of $0.5 \mathrm{~mm}$ Thickness (Left) and the Position of Cutting Out in a Coating Layer (Right).

Table 1. Density and Oxygen Content of the Copper Specimens

\begin{tabular}{c|c|c|c}
\hline Number & Description & Density $\left(\mathrm{g} / \mathrm{cm}^{3}\right)$ & Oxygen content $(\%)$ \\
\hline$\# 1$ & Low-purity copper on stainless steel SS 304 & 8.72 & 0.33 \\
\hline$\# 2$ & High-purity copper on stainless steel SS 304 & 8.90 & 0.019 \\
\hline$\# 3$ & Low-purity copper on nodular cast iron & 8.72 & 0.32 \\
\hline$\# 4$ & Extruded copper & 8.86 & 0.065 \\
\hline$\# 5$ & Forged copper & $8.9^{*}$ & $0.06^{*}$ \\
\hline
\end{tabular}

* Estimated Value from a Extruded Copper 


\section{CORROSION EXPERIMENT}

\subsection{Electrochemical Polarization Test}

A polarization test was performed at room temperature for the CSC specimens described in Table 1. The test was done in a flat cell kit (Fig. 6), which comprised a Pt wire mesh $(2.5 \mathrm{~cm} \times 2.5 \mathrm{~cm})$ as a counter electrode, an $\mathrm{Ag} /$ $\mathrm{AgCl} /$ (saturated $\mathrm{KCl})$ reference electrode, and a round plate seat of $1 \mathrm{~cm}^{2}$ in an area sealed by a Teflon O-ring, in which a test coupon was placed as a working electrode. A test coupon (diameter $15 \mathrm{~mm}$, thickness $1 \mathrm{~mm}$ ) was polished with No. 2,000 sandpaper and $0.3 \mu \mathrm{m}$ alumina slurry successively, and the polished surface was cleaned with alcohol and washed with distilled water. A test solution was made by dissolving $175.4 \mathrm{~g}$ of $\mathrm{NaCl}$ (Min. 99.5\% purity by DC Chemical Co.) in $1 \mathrm{~L}$ of deionized water resulting in $3 \mathrm{~mol} / \mathrm{L}$ concentration. A voltage scan was carried out at $10 \mathrm{mV} / \mathrm{sec}$ ranging from $-1.5 \mathrm{~V}$ to $1.0 \mathrm{~V}$ with $\mathrm{N}_{2}$ purging. After the polarization tests, the test specimens were washed with distilled water to remove any remaining salt on the surface, and then the surface was surveyed optically.

\subsection{Immersion Test in Acidic Solution}

A brief corrosion test was performed to compare the CSC coppers with other commercial coppers by immersing them in an acidic $\mathrm{HCl}$ solution. Then, their weight losses were measured at room temperature. The corrosion product of copper does not remain on the surface and is easily dissolved in the acidic solution in this test condition. Thus, this test is useful to estimate the corrosion of a copper metal itself without the protective effect of a corrosion layer. The specimens were prepared as rectangular strips $(8.6 \times 20 \times \mathrm{t} 1.0 \mathrm{~mm})$ and their surfaces were polished
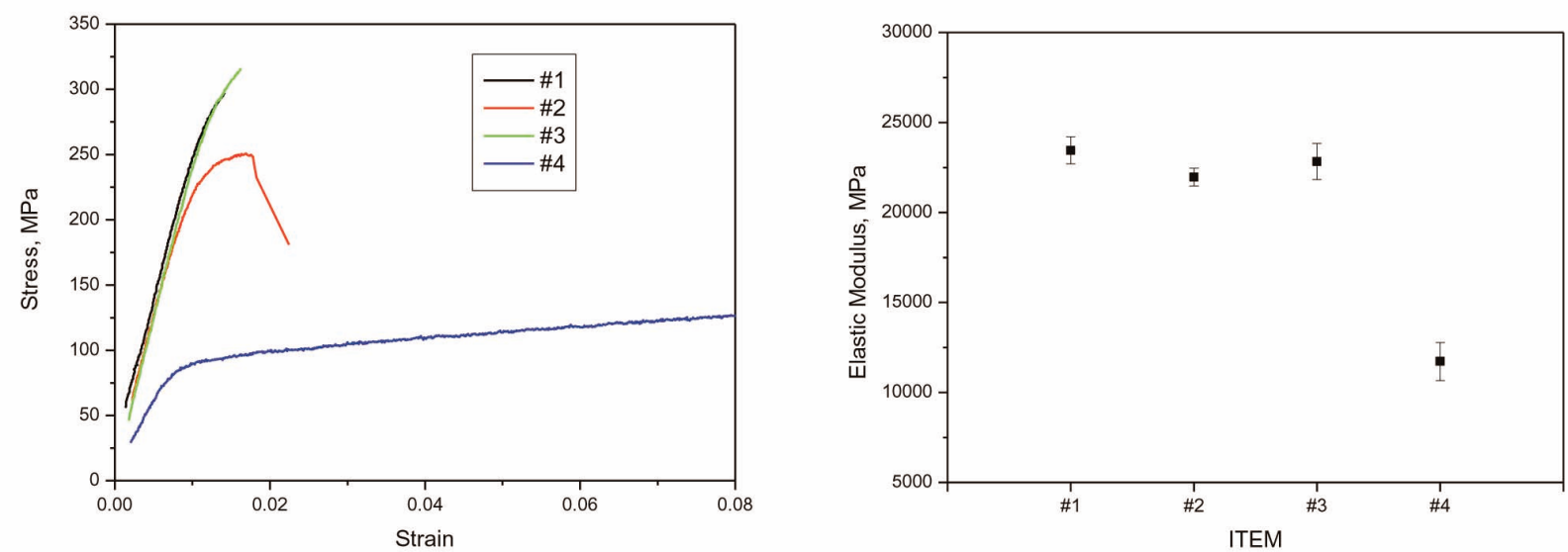

Fig. 5. Stress-strain Curves (Left) and Elastic Moduli (Right) of the copper Specimens (\#1; Low-purity CSC Copper on SS 304, \#2; High-purity CSC Copper on SS 304, \#3 Low-purity Copper on Cast Iron, \#4 Extruded Copper)

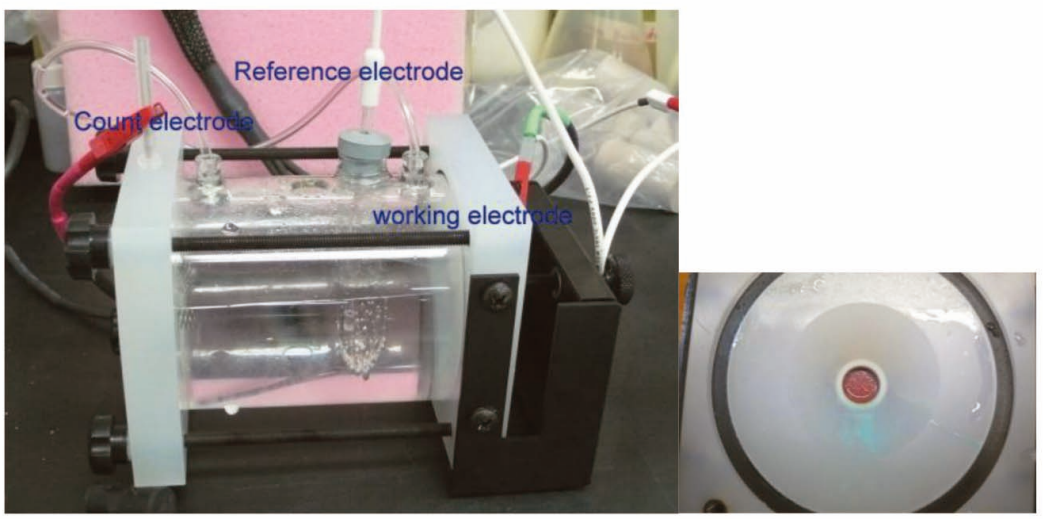

Fig. 6. Flat Cell kit (Left) and Working Electrode (Right) after Testing 
with a No. 2,000 sandpaper and finished with $0.3 \mu \mathrm{m}$ alumina slurry. The specimens were submerged in the acidic solution and subjected to ultrasonic vibration for five minutes. The weight loss was measured using a mass balance at five minute intervals.

\subsection{Humid Air Test}

A second corrosion test was performed on the copper specimens in humid air. Copper is known to be easily oxidized in air with the aid of oxygen and vapor, but it reveals good corrosion resistance immediately after oxidation due to a strong and inert oxide film on the surface $[20,21]$. To verify the protective effect of oxide products against corrosion, the CSC copper was oxidized in humid air together with other coppers. To activate the oxidation reaction, the test temperature was raised to $70^{\circ} \mathrm{C}$, which is the expected maximum temperature on a disposal canister surface in a deep geologic disposal plan which is being developed by Korea Atomic Energy Research Institute (KAERI) [22]. The rectangular strips $(8.6$ x $20 \mathrm{x}$ t1.0 $\mathrm{mm}$ ) were prepared in exactly the same manner as those in the previous immersion test. A flat bottomed $1 \mathrm{~L}$ glass bottle with a sealing lid was prepared for this test. A thin hydrophobic cloth was placed on the inside bottom surface of the glass bottle. Then, specimens and a piece of soaked towel were placed on the cloth separately not in contact with each other. Finally, the bottle was closed and put in an environmental chamber. The copper specimens were oxidized for about two months in a saturated humidity at $70^{\circ} \mathrm{C}$. After the test, the oxidation product formed on the surface was removed by an aqueous $2.5 \% \mathrm{HCl}$ solution for about 20 seconds, and then the weight loss was measured for the copper specimens.

\section{CORROSION TEST RESULTS AND DISCUSSION}

\subsection{Polarization Test}

The basic electrochemical properties of the CSC specimens were estimated through a polarization test at room temperature. The test results are summarized in Fig. 7. From the curves, some differences could be observed between the CSC coppers and the other commercial coppers. Unlike commercial coppers, the most distinguishable feature of the CSC coppers was passivation behavior at around $-0.25 \mathrm{~V}$. From this, the formation of $\mathrm{Cu}_{2} \mathrm{O}$ can be inferred in this region which could act as a protective barrier against oxidants [23]. Considering this passive behavior occurred only in the CSC coppers and was stronger in low-purity coppers (\#1 \& \#3) than high-purity copper (\#2), the passive behavior seems to be related with the small amount of oxide at the interface of the stacked copper particles. Another passive behavior of all the copper specimens developed at around $+0.25 \mathrm{~V}$ due to the formation of $\mathrm{CuCl}[24,25]$. The degree of passivity

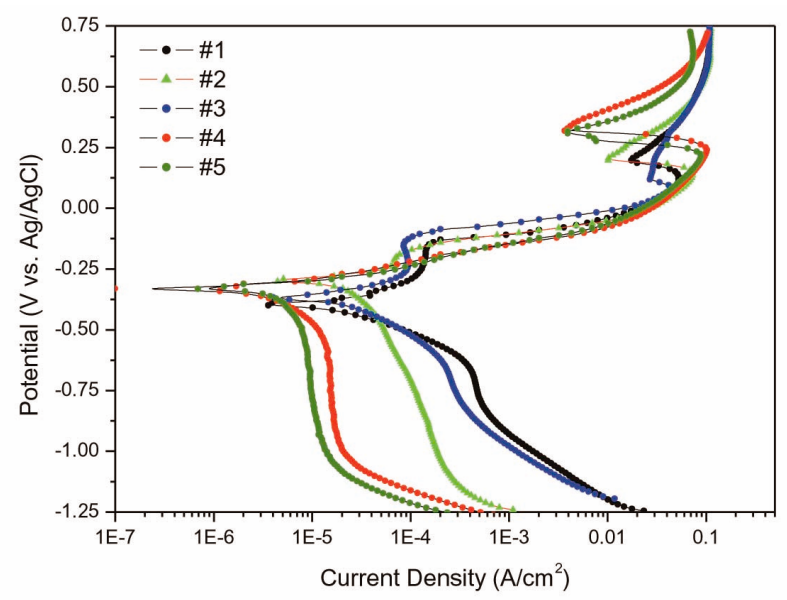

Fig. 7. Polarization Curves of the Copper Specimens (\#1; Low-purity Copper on SS 304, \#2; High-purity Copper on SS 304, \#3 High-purity Copper on Cast Iron, \#4 Extruded Copper, and \#5 Forging Copper)

in the commercial coppers (\#4 and \#5) was stronger than that of the coating coppers (\#1 to \#3) in this region, which means that the passive film formed on the CSC specimens is less protective than that of commercial coppers.

Tafel analysis was attempted for the above polarization curves to obtain a corrosion potential and corrosion current. Fig. 8 shows the result of the Tafel analysis. The corrosion potential was related to the copper purity regardless of the copper type. The high-purity CSC copper (\#2) revealed the highest corrosion potential, the extruded (\#4) and forged copper (\#5) were the next, and the low-purity CSC coppers (\#1 and \#3) were the lowest. This suggests that the method of copper specimen formation had little influence on the corrosion potential, but the oxygen content, as a degree of impurity, had an apparent influence. The corrosion current at corrosion potential is converted to a corrosion rate in Fig. 8. Actually, the corrosion rates from the Tafel analysis were derived from an active metal itself without a passive film on the surface. The CSC specimens (\#1 to \#3) revealed higher corrosion rates than the commercial coppers (\#4 and \#5), which means that the CSC coppers were less corrosion resistant. Among the CSC specimens, the high-purity CSC copper (\#2) had a relatively lower corrosion rate.

Optical micrographs of the test specimens are shown in Fig. 9. Many convex dots were observed on the surface of the CSC coppers, and the size of the dots ranged from 10 to $50 \mu \mathrm{m}$ which was nearly the same as that of copper powder used in a CSC process. The density of the dots decreased on the surface of pure copper (\#2). This can be considered a typical feature of CSC coppers since this was not observed with the commercial coppers (\#4 and \#5). It is supposed that the dots originated from poor copper 

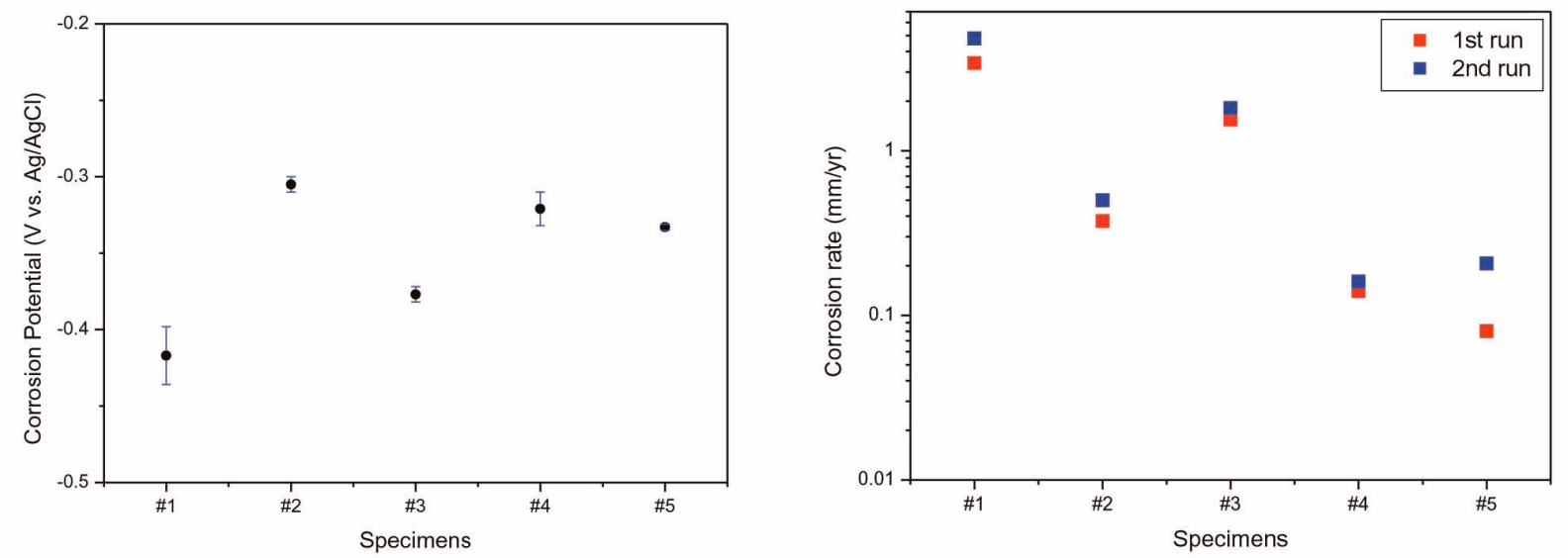

Fig. 8. Corrosion Potential (Left) and Corrosion Rate (Right) of Copper Specimens Derived from Tafel Analysis of Polarization Curves
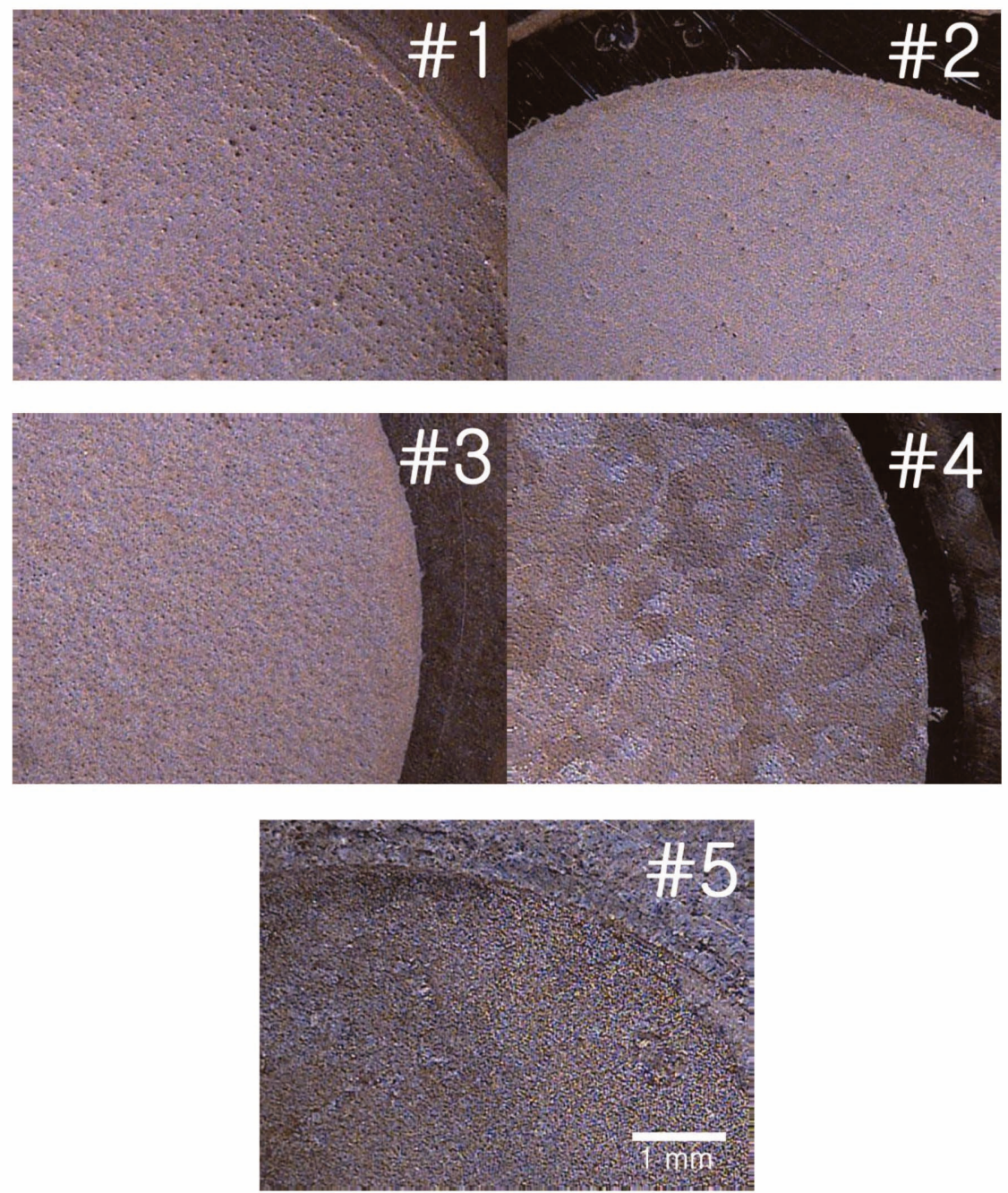

Fig. 9. Optical micrograph of Copper Specimens from Polarization Tests of Fig. 5 


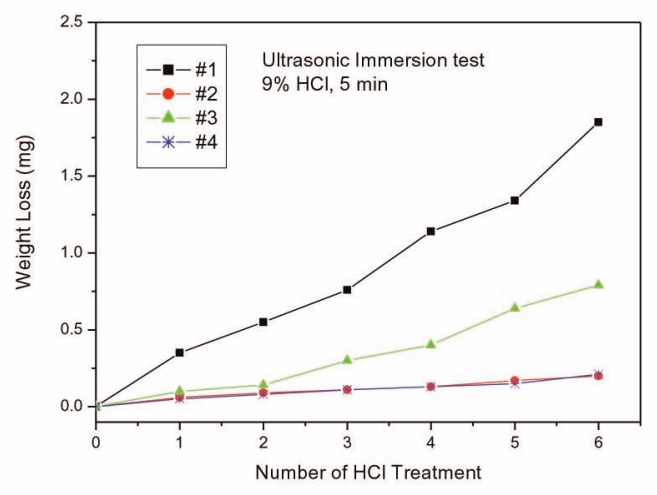

(a)

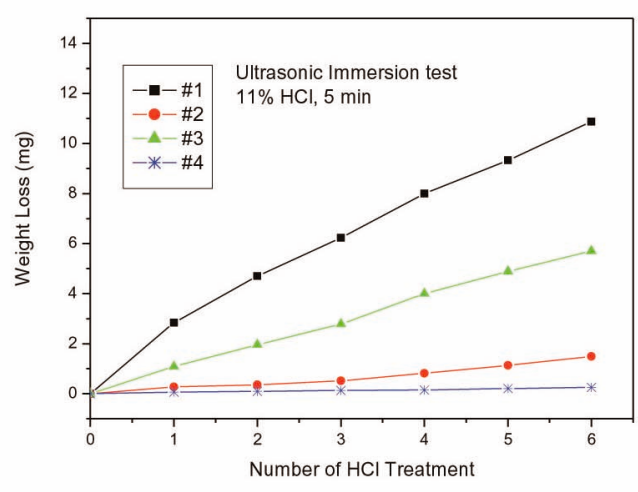

(c)

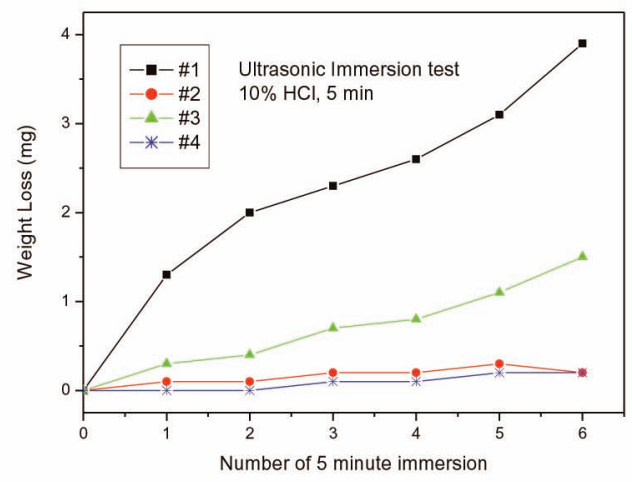

(b)

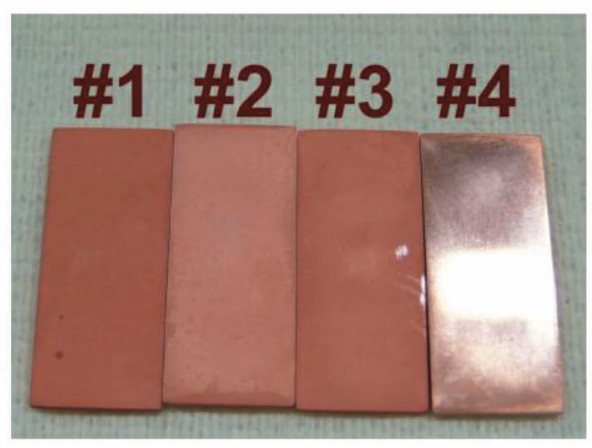

(d)

Fig. 10. Weight Loss Curves of Copper Specimens in Various Aqueous HCl Solutions of (a) 9 wt $\%$, (b) $10 \mathrm{wt} \%$, (c) $11 \mathrm{wt} \%$, and the Resulting Photo (d) from (c). (\#1; Low-purity Copper on SS 304, \#2; High-purity Copper on SS 304, \#3 Low-purity Copper on Cast iron, \#4 Common Copper)

particles, the surface of which was covered by oxide. The commercial coppers (\#4 and \#5) revealed a relatively uniform corrosion surface. A granular structure was clearly seen in the case of the extruded copper (\#4). The forged copper (\#5) exhibited very fine crystalline granules as seen in a scanning electron microscopic survey, although these granules are not clear in this optical micrograph.

\subsection{Immersion Test in Acidic Solution}

The results of the immersion test are summarized in Fig. 10. All the specimens showed a steady decrease in their weight. The CSC copper (\#1) corroded at the highest rate, and the CSC copper (\#3) was the next. However, the high-purity CSC copper (\#2) revealed less weight loss from the acid immersion test and exhibited nearly the same weight loss pattern as the commercial copper (\#4). This result indicates that the copper with higher oxygen content was more corrosive, and the CSC coppers were less corrosion resistant than the commercial copper (\#4) in acidic conditions. The (\#1) and (\#3) curves in Fig. 10 reveal different corrosion rates, even though they were derived from the same copper powders. The reason is uncertain, but it is presumed that the (\#1) specimens might be formed with a poor compaction of the copper particles during their CSC process.

\subsection{Humid Air Test}

The results of the humid air test are summarized in Fig. 11. Unlike the acidic solution corrosion, the humid air corrosion product of copper remains on the surface as a passive film, which resists further oxidation of the test specimen. Therefore, it would be possible to estimate the shielding performance of the passive film from oxidants by this test. All the copper specimens showed rapid corrosion during the initial period, but the curves of weight loss stabilized within several days for all coppers due to the effect of a formed passive film. As seen in Fig. 11, the high-purity CSC copper (\#2) and the forged copper (\#5) 

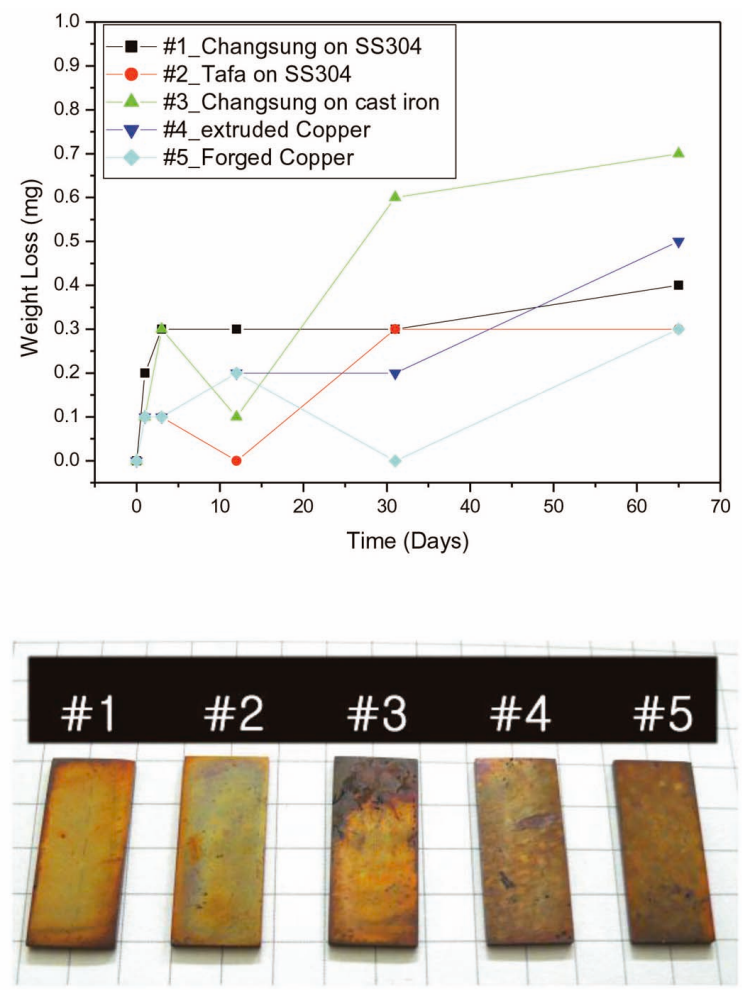

Fig. 11. Weight Loss Curves of Copper Specimens in Humid Air and the Resulted Specimen Photos. (\#1; Low-purity Copper on SS 304, \#2; High-purity Copper on SS 304, \#3 Low-purity Copper on Cast Iron, \#4 Common Copper)

had better corrosion resistance than the others specimens at an initial stage. Then, after 30 days, the low-quality CSC coppers (\#1 and \#3) also showed very little increase in weight loss. From this result, it was estimated that the CSC coppers could also form a good corrosion resistant passive film.

\subsection{Summary}

The results of the three tests suggest that CSC copper was not better than commercial coppers in corrosion resistance. However, considering that the corrosion resistance of copper is due to its passive film from corrosion activity and CSC coppers also showed such a corrosion resistance as result of the humid air test, the CSC method still seems to be a valid alternative in the fabrication of a large copper canister.

Copper corrosion may be evaluated in terms of three factors. The first factor is whether the environment is oxidative or reductive, which is related to the corrosion potential. The corrosion potentials of CSC coppers were measured by electrochemical polarization testing in this study. The second factor is the corrosion rate of metallic copper itself in a corrosive environment. The weight loss of CSC coppers was measured in an acidic solution to test this. Finally, the third factor is the stability of the corrosion product which can act as a passive film. This is closely related with the long-term corrosion behavior of copper. A humid air test was applied to test this factor.

Unfortunately, the lifetime of a copper canister in an underground environment cannot be demonstrated from the simple tests described above because corrosion is closely related to types of oxidants and the stability of a corrosion product in an underground environment. Therefore, it is necessary to know the deep geological environment. According to the KAERI HLW disposal site design [22], the disposal canister for HLW will be buried in saturated granite rock about $500 \mathrm{~m}$ deep, like in Sweden and Finland. The deep geologic environment lacks oxygen or other oxidants. Moreover its oxidation/ reduction potential is too low to oxidize copper. In addition, the disposal canister will be surrounded by a thick bentonite buffer to suppress the permeation of oxidants from the environment. Thus, the corrosion rate of a copper canister may be very low in this environment, although the corrosion process may continue ceaselessly over a very long period of time. Therefore, if we want to know the correct lifetime of a copper canister, a long-term test in a real environment is essential. 


\section{CONCLUSIONS}

A cold spray coating technique was studied to form a $10 \mathrm{~mm}$-thick copper layer on metal substrates for its application to a HLW disposal canister. We fabricated thick copper coatings using two kinds of copper powders with different purities. The result of tensile testing showed that the CSC coppers had a high tensile strength but were brittle in comparison with commercial coppers. Evaluation of the corrosion behavior of CSC coppers was carried out by comparison with commercial coppers in three tests. Electrochemical polarization testing showed that the corrosion potentials of the CSC coppers were dependent on their purity but not on their method of manufacture. However, the corrosion rate was a little higher in the CSC coppers than the commercial coppers as result of corrosion current in Tafel analysis and an aqueous 10wt $\%$ $\mathrm{HCl}$ solution test. Thus, we determined that the CSC copper itself is slightly more vulnerable to corrosion than commercial coppers, but the suppression of corrosion was confirmed by humid air testing which demonstrated the formation of a passive film. Therefore, it was concluded that the CSC method could be applied in the manufacture of HLW disposal canisters because no significant corrosion problem is expected for CSC copper in underground environment. To further clarify these findings, more experiments, such as a field test for the CSC copper would be beneficial.

\section{ACKNOWLEDGEMENT}

This work was carried out as a part of the mid- and long-term nuclear R\&D plans funded by the Ministry of Science and Technology, Korea.

\section{REFERENCES}

[1] Nuclear Waste Bulletin No. 14, Nuclear Energy Agency Organization for Economic co-operation and Development, 2000.

[2 ] C.G. Andersson, "Development of Fabrication Technology for Copper Canisters with Cast Inserts", Technical report TR-02-07, SKB (2002).

[3] H. Raiko, J. P. Salo, "Design Report of the Canister for Nuclear Fuel Disposal", Report 96-13, POSIVA (1996).

[4] Japan Nuclear Cycle Development Institute, "Project to Establish the Scientific and Technical Basis for HLW Disposal in Japan", H12 Report, JAEA (2000).

[5] N. Taniguchi, M. Kawasaki, and M. Naito, "Effect of Sulfide on the Corrosion Behavior of Pure Copper under Anaerobic Condition and Possibility of Super Long Lifetime for Copper Overpacks", JAEA-Research 2007-022, JAEA (2007) (in Japansese).

[6] D.W. Shoesmith, "Assessing the Corrosion Performance of High-Level Nuclear Waste Containers ”, Corrosion, 62(8),
703 (2006).

[7] M. Pourbaix, Atlas of Electrochemical Equilibria in Aqueous Solutions, Pergamon, 1966.

[ 8 ] D.G. Brookins, Eh-pH Diagrams for Geochemistry, Springer-Verlag, 1988.

[9] J. Lee, H.J. Cho, and J. Choi, "Concept of a Korean Reference Disposal System for Spent Fuels", J. Nucl. Sci. Technol. 44, 1565 (2007).

[10] Swedish Nuclear Fuel and Waste Management Co., "RD \& D Programme 2007", Technical Report TR-07-12, SKB (2007).

[11] W. H. Bowyer, "Design Basis For The Copper/Steel Canister", SKI Report 98:29, SKI (1998).

[12] W. H. Bowyer, "A Study of Defects which Might Arise in the Copper Steel Canister", SKI Report 00:19, SKI (1999).

[13] S.S. Kim, K. S. chun, J. W. Yeon, and J.W. choi, "Corrosion of the Candidate Materials for the Disposal Container of a High-Level Radioactive Waste", J. the Korean Radioactive Waste Society, 23, No. 2, 97 (2006).

[14] B. Kursten, E. Smailos, I.Azkarate, L. Werme, N.R. Smart, and G. Santarini, COBECOMA (State-of-the-art document on the COrrosion BEhaviour of Container Materials), Final report, EUROPEAN COMMISSION, (2003).

[15] U.S. Department of Energy, "Science and Technology Program Plan", DOE/RW-0576, DOE, (2005).

[16] C. G. Andersson, "Test Manufacturing of Copper Canisters with Cast Inserts", Technical report TR-98-09, SKB (1998).

[17] A. Papyrin, "Cold Spray Technology", Advanced Materials \& Processes, 49 (2001)

[18] Nuclear Energy Agency, "Engineered Barrier Systems and the Safety of Deep Geological Repositories", ISBN 9218498-8, NEA (2003).

[19] C. G. Andersson, P. E., and M Westman, , "Status Report, Canister Fabrication" Technical report TR-04-23, SKB (2004).

[20] T. Aastrup, M. Wadsak, M. Schreiner, and C. Leygraf, "Experimental in situ studies of copper exposed to humidified air", Corrosion Science, 42, 957 (2000)

[21] K. P. FitzGerald, J. Narirn, G. Skennerton, and A. Atrens, "Atmospheric corrosion of copper and the colour, structure and composition of natural patinas on copper", Corrosion Science, 48, 2480 (2006)

[22] Korea Atomic Energy Research Institute, "High-Level Radwaste Disposal Technology Development", Research report RR-2765, KAERI (2006). (in Korean)

[23] J. Ambrose, R. Barradas, and D. W. Shoesmith, "Investigations of Copper in Aqueous Alkaline Solutions by Cyclic Voltammetry", J. Electroanal. Chem. \& Interfacial Electrochem., 47, 47 (1973).

[24] A. D. Modestov, G. D. Zhou, H. H. Ge, B. H. Loo, "A Study by Voltammetry and Photocurrent Response Method of Copper Electrode Behavior in Acidic and Alkaline Solutions Containing Chloride ions", J. Electroanal. Chem., 380, 63 (1995).

[25] J. Crousier, L. Pardessus, J. P. Crousier, "Voltammetry Study of Copper in Chloride Solution", Electrochim. Acta, 33, 1039 (1988). 